\title{
Atomic contacts via electrochemistry in water/cyclodextrin media: a step toward protected atomic contacts
}

Yann. R. Leroux, Claire Fave, Dodzi Zigah, Gaelle Trippe-Allard, Jean Christophe Lacroix*

\section{SUPPORTING INFORMATIONS}



Figure SI1: Conductance versus time during the electrochemical process in a) water; $b$ ) water $+7.10^{-4} \mathrm{M}$ glucose; $\mathrm{c}$ ) water $+10^{-4} \mathrm{M} \beta-\mathrm{CD}$.

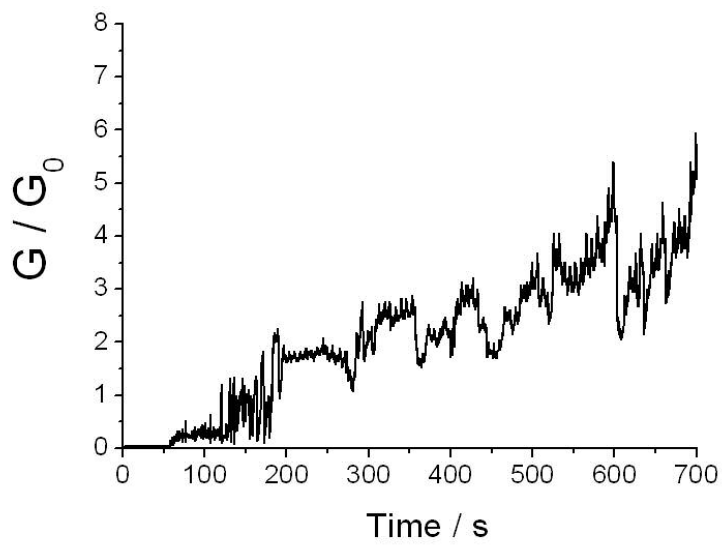

Figure SI2: Conductance versus time during the electrochemical process in water/calixarene. 

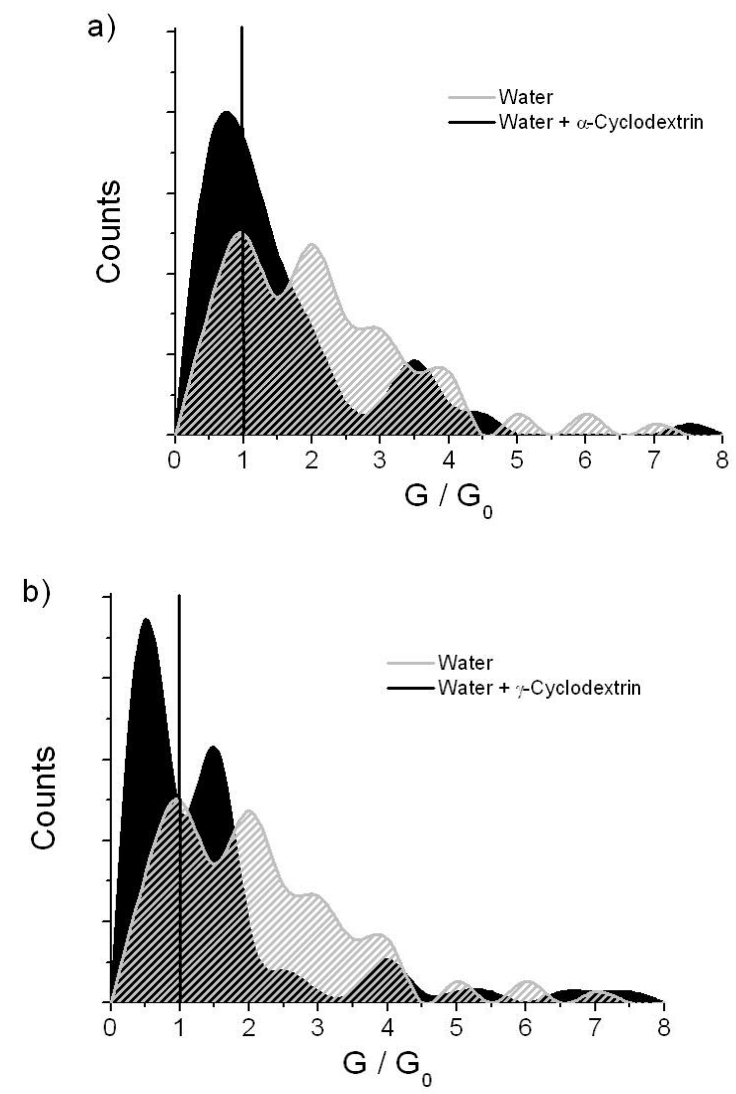

Figure SI3: Conductance Histograms obtained a) in water/ $\alpha-C D$ and $b$ ) in water $/ \gamma-C D$.

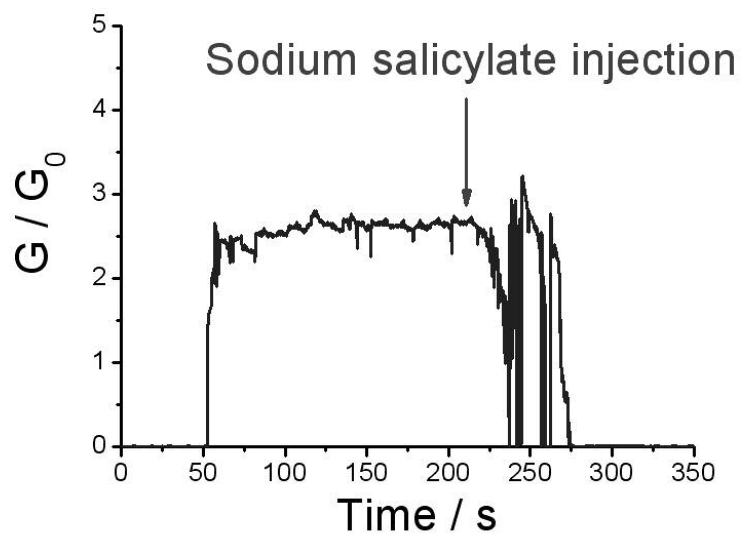

Figure SI4: Effect of sodium salicylate injection on an atomic contact generated in water/glucose 